\title{
LETRAMENTO DIGITAL: REFLEXOS NO MUNDO DO TRABALHO
}

DIGITAL LITERACY: REFLECTIONS ON THE WORLD OF WORK

\author{
Luisa Nascimento Bustillo \\ Grasiele Augusta Ferreira Nascimento
}

\begin{abstract}
Resumo
0 presente artigo busca verificar como o desenvolvimento de novas tecnologias reorganizam o mundo do trabalho. Objetiva-se entender se o trabalho, reestruturado pelos mencionados recursos, preserva seu caráter de direito social, protegendo a dignidade da pessoa humana, por meio do contraste da promessa de inclusão no mundo do trabalho com sua real reorganização em frente à absorção das tecnologias de informação, considerando aspectos que nem sempre integram a entusiasmada recepção de inovações. 0 estudo, fundamentado no método interpretativo-dedutivo de investigação em pesquisa bibliográfica e documental, aborda o conceito de letramento e letramento digital e o trabalho como direito social constitucional.
\end{abstract}

Palavras-chaves: Letramento digital. Inclusão social. Mercado de trabalho.

\begin{abstract}
The present article aims to verify how the development of new technologies reorganizes the world of work. The objective is to understand if work, restructured by the aforementioned resources, preserves its social character, protecting the dignity of the human person, by the contrast of the promise of inclusion in the world of work with its real reorganization against the absorption of information technologies, considering aspects that do not always integrate the enthusiastic reception of innovations. The study, grounded on the interpretative-deductive method of research in bibliographical and documentary research, addresses the concept of digital literacy and work as a constitutional social right.
\end{abstract}

Keywords: Digital literacy. Social inclusion. Labor market. 


\section{INTRODUÇÃO}

O presente trabalho visa analisar como o desenvolvimento de novas tecnologias, a partir de mudanças provocadas no próprio indivíduo, atingem e reorganizam o mundo do trabalho, desde o aspecto do acesso a este até suas relações internas.

As características das novas gerações estão, atualmente, remoldando as relações de trabalho. Nascidos imersos em uma cultura permeada pelo letramento digital, a geração "Y" e as subsequentes possuem uma diversidade de identidades transcendentes, comportamentos modelados pela integração online, e modos de pensar que refletem a internet e seu enfoque múltiplo, gerando um contingente trabalhador com alta produtividade e criatividade, mas com uma relação com o trabalho diversificada. 0 mundo do trabalho passa, atualmente, por transformações e adaptações para incluir os novos recursos tecnológicos em seu meio, com diversas finalidades: aumentar a produção e diminuir seu tempo, melhorar taxas lucrativas, dentre outros aspectos. Nem sempre, contudo, é equacionado nessa expressão o trabalho como direito social.

0 presente artigo visa expor, ainda, que na sociedade contemporânea, acerca de novas tecnologias, há uma ideia profética de intensificação de integração de indivíduos na sociedade, dado o estreitamento de laços, diminuição de distâncias físicas e enorme difusão de informação que elas podem propiciar. Igualmente, pretende-se analisar tal promessa com relação à inclusão no mundo do trabalho e sua reorganização frente à absorção das tecnologias de informação e comunicação (TICs).

Dessa maneira, faz-se necessário considerar que os avanços tecnológicos também possuem aspectos negativos, tanto para aqueles que possuem o domínio sobre eles (e têm o chamado "letramento digital"), quanto para quem não compactua dessas práxis modernas. Estes aspectos nem sempre são aparentes e nem sempre são levados em consideração na entusiasmada recepção social de inovações.

Assim, este artigo, por meio do método interpretativo-dedutivo de investigação em pesquisa bibliográfica e documental, objetiva analisar os diversos efeitos e desdobramentos das novas tecnologias e do letramento digital no mercado de trabalho e nas relações de trabalho e, para 
tanto, abordará o conceito de letramento e letramento digital, bem como o trabalho sendo um direito social garantido constitucionalmente como exponente proteção da dignidade da pessoa humana.

\section{CONCEITO DE “LETRAMENTO” E “LETRAMENTO DIGITAL”}

Antes que seja possível fazer qualquer consideração sobre letramento digital ou seus impactos no mundo do trabalho, é necessário conceituar, primeiramente, o "letramento". Faz-se interessante, igualmente, traçar um paralelo entre o letramento que diz respeito às práticas envolvendo a escrita e aquele que se dá na mediação pelas tecnologias de informação e comunicação (TICs).

É preciso destacar, que tal definição é, ainda, um tanto quanto polêmica conforme exposto por Kleiman (2014, p. 74). Mesmo diante de certa polissemia na literatura do assunto, o conceito começa a tomar forma no Brasil a partir da exposição de Soares (1995, p. 7), para quem letramento corresponde ao estado ou condição de quem pratica a escrita em conjunto (ou alternativamente) com o exercício das práticas sociais nas quais a escrita tem um papel significativo (1995, p. 7). Posteriormente, a mesma autora elabora que letramento é o estado ou condição de quem exerce as práticas sociais de leitura e de escrita, de quem participa de eventos em que a escrita é parte integrante da interação entre pessoas e do processo de interpretação dessa interação (SOARES, 2002, apud BUZAT0, 2006).

Assim, ser letrado é diferente de ser meramente alfabetizado ${ }^{1}$. 0 alfabetismo pressupõe o domínio do código da linguagem, mas não seu efetivo uso no meio social, como o faz o letramento. Sintetizando, Marcuschi revela que letrado "é o indivíduo que participa de forma significativa de eventos de letramento e não apenas aquele que faz uso formal da escrita" (2001, p. 25).

É nesse contexto que surge a diferenciação de níveis de alfabetismo e de analfabetismo funcional, classificando-se em escala a habilidade de se participar efetivamente de práticas de determinado grupo ou comunidade nas quais o letramento é necessário (UNESCO, tradução nossa, 
1978, p. 18, anexo I), sendo o analfabeto funcional quem decodifica o código da linguagem gráfica, mas não consegue engajar-se em outras operações a partir disso.

Assim, o letramento se anuncia na funcionalidade, no impacto que a escrita pode proporcionar na sociedade, permeado por uma forma de agir e uma visão de mundo partilhada por um grupo, carregando traços identitários e significados partilhados por tal aglomeração (BUZATO, 2008).

Não se pode esquecer que a codificação em grafia é a maior revolução tecnológica já ocorrida na história da humanidade. Por tão intrincada no dia a dia, é fácil esquecer que a escrita é, em si, uma tecnologia, que carrega como outras (conforme exposto mais à frente) a dicotomia de inclusão e exclusão. Ilustrando o conflito, Buzato expõe que: “[...] a escrita inaugurou o analfabetismo como um problema, mas também trouxe formas de democratizar e massificar o conhecimento [...]" (BUZATO, 2006, on-line).

Em linha semelhante, Magda Soares (1995, p. 12) explicita que o domínio da escrita "pode ser um instrumento tanto para a libertação quanto para a domesticação do homem, dependendo do contexto ideológico em que ocorre, Freire evidencia a natureza política". A autora explica que as consequências daquele domínio são

[...] consideradas desejáveis e benéficas apenas por aqueles que não questionam a natureza e a estrutura da sociedade; quando isso não ocorre, isto é, quando a natureza e a estrutura das relações das práticas sociais são questionadas, o alfabetismo é visto como um instrumento ideológico que apenas mantém as práticas e relações sociais vigentes, acomodando as pessoas às circunstancias existentes. (SOARES, 1995, p. 12).

Soares, então, denuncia a crença amplamente aceita, que aos poucos começa a ser contestada, de que o alfabetismo, o domínio do código, tem o poder, por si só, de promover o "progresso social e individual", com consequências necessariamente e apenas positivas (1995, p. 11). Esse tipo de crença possibilitou práticas escolares que não fomentam senso crítico ou maiores problematizações sobre a participação na sociedade e a formação de indivíduos alfabetizados, mas não "letrados" em sua integralidade.

Entretanto, com a evolução de novas tecnologias, agora em sua maioria com interfaces digitais, sua instauração no cotidiano mundial, 
bem como com o acentuado e crescente uso de computadores, tablets e celulares para práticas sociais diversas (como por exemplo, no trabalho), foi necessário cunhar o termo "letramento digital".

Novas mídias moldam, igualmente como a escrita o fez, inovadoras práticas sociais até em seu aspecto mais básico, como a comunicação. Práticas cotidianas foram absolutamente revolucionadas e mais uma vez, a oralidade foi preterida, dando lugar a e-mails, mensagens de texto instantâneas, etc.

Assim, novas práticas sociais específicas nasceram, englobando os novos recursos tecnológicos à disposição da sociedade, exigindo dos indivíduos uma reorganização em diversos níveis da vida.

Isso porque, segundo Buzato (2006, on-line), "a tecnologia, a exemplo da linguagem, tanto molda e organiza relações [...] como é, ao mesmo tempo, moldada e organizada por essas mesmas forças [...]". Trata-se de "conceber a tecnologia como ação social coletiva, como rede de enlaces entre atores humanos e não humanos, e o seu desenvolvimento como um processo de desvios, derivas, deslizamentos e translações sucessivos (Latour, 2000)" (BUZAT0, 2008, on-line).

Desse modo, com a inserção desses recursos na sociedade de modo geral, espera-se do indivíduo que este adquira habilidades básicas que possibilitem o uso destes (em paralelo com dominar o código da linguagem), mas não só: espera-se que ele seja capaz de utilizar tais para concretizar interesses, necessidades, iniciativas tanto individuais como comunitárias, tendo autonomia para figurar nas práticas sociais formadas nesse contexto, ou seja, além da mera familiaridade com tais recursos, requer-se o letramento digital.

A partir disso, é necessário expor o conceito de letramento digital dado por Buzato:

Letramentos digitais (LDs) são conjuntos de letramentos (práticas sociais) que se apoiam, entrelaçam, e apropriam mútua e continuamente por meio de dispositivos digitais para finalidades específicas, tanto em contextos socioculturais geograficamente e temporalmente limitados, quanto naqueles construídos pela interação mediada eletronicamente. (KLEIMAN, 2006, p. 06, apud BUZATO, 2008). 
Os conceitos apresentados, de "letramento" e "letramento digital", importam porque determinam o tratamento do fenômeno (ou por vezes da sua ausência) de maneiras diferentes por governos, empresas, escolas, etc. Por exemplo, os governos podem focar na simples difusão, para a massa da população, de aspectos técnicos de tais tecnologias (ex. como ligar um computador, o que é a internet, etc.). Mas será só isso o necessário para que se adquira a autonomia que o letramento digital propicia? As políticas públicas precisam ser definidas, levando todos os aspectos dos conceitos em consideração.

Como ressaltado, as novas tecnologias de informação e comunicação inseriram-se nos diversos aspectos da vida em sociedade. Juntamente com elas, certo fetichismo se instaurou no imaginário social, atrelando ao avanço tecnológico uma ideia de benesse sem ressalvas.

\section{A ERA DIGITAL E A ILUSÃO INCLUSIVA}

As inovações no campo das TICs ocorreram em um ritmo extremamente acelerado nas últimas décadas. A era digital instaurou-se como modeladora de comportamentos e relacionamentos, implantando recursos tecnológicos em todos os aspectos da vida em sociedade.

Com esse novo panorama, a promessa de onipresença se instalou no senso coletivo: a internet possibilitaria a todos estar em vários lugares ao mesmo tempo, acessar informações provenientes de diversas fontes e interagir em diferentes esferas sem as barreiras físicas mundanas. Conforme Kleiman e Vieira (2006, p. 121): “a mobilidade e o livre trânsito, livre das amarras sociais, de contornos geográficos e da estratificação, por essa espécie de paraíso cibernético, certamente conferiria certa onipotência ao sujeito".

No senso coletivo, as novas gerações, como a "geração $\mathrm{Y}^{\prime 2}$, possuem quase como pressuposto intrínseco o letramento digital, sendo composta por jovens familiarizados com as potencialidades dos recursos em pauta. Ainda, por esse senso, de uma maneira geral, são pessoas marcadas, em sua identidade, pela tecnologia, exercendo a onipresença supracitada e transitando livremente sobre o "paraíso cibernético" de Kleiman e Vieira (2006, p. 121). 
Existe, claramente, no contexto delineado, um tipo de fetiche pela tecnologia presente na sociedade. Novaes e Dagnino (2004, p. 195), ao refletir sobre a tecnologia e seu papel para a democracia, apontam os autores Noble e Feenberg como filósofos que enxergam:

[..] um fetiche cultural na tecnologia e afirmam que este reside no foco naquilo que está na moda, na mudança contínua, incessante da tecnologia, e na ideia de avanço inexorável sempre benéfico. No entanto, nos esquecemos naquilo que não está mudando, isto é, das relações de dominação que continuam a moldar a sociedade e a tecnologia (NOBLE, 1984, apud NOVAES; DAGNINO, 2004, p. 195).

Assim, variados autores já começam a advertir que a era digital não cumpre todas as suas promessas, por diferentes motivos. Kleiman (2014, p. 75) aponta que: "essas recomposições identitárias, baseadas no acesso à informação, no entanto, não são universais [...]”. Buzato (2006), por sua vez, aponta que a camada que, entretanto, não possui tamanha integração com essas novas concepções, vê-se absolutamente excluída, não só, do mercado de trabalho, mas de práticas cotidianas.

Isso porque, ao mesmo tempo que os recursos em questão inovam quanto a possibilidades de interação, pesquisa, etc., "as novas tecnologias da informação e da comunicação [...] estão relacionadas à produção de 'desconectados' ou 'excluídos' (BUZATO, 2006, p. 02, apud BUZATO, 2008). Desse modo, quem não possui um mínimo de acesso e controle sobre tais recursos poderá ter cerceada sua participação no mercado de trabalho (tendo como reservados, neste, apenas subempregos, por exemplo), assim como em outras facetas da vida, num ciclo vicioso que, se não amparado por políticas públicas, apenas acirrará desigualdades.

Este não é um fenômeno novo ou mesmo exclusivo da era digital. Novos recursos tecnológicos tendem a

[...] tomar a forma de uma "caixa-preta" (Latour, 2000), algo como uma sobra que começa a permear relações sociais e culturais, a influencias na construção, distribuição valorização e transformação do conhecimento, e a definir quem está incluído e quem não está (BUZATO, 2006, on-line). 
O referido autor ainda cita exemplos como a imprensa, a eletricidade, o automóvel, o telefone, etc. e evidencia que, inicialmente, tais tecnologias possuíam seu acesso muito restrito, de modo que são "vistas por uns como soluções messiânicas e por outros como cavaleiros do apocalipse" (BUZATO, 2006, on-line) e conforme vão se imiscuindo no cotidiano, vão se resignificando e dando novo significado também aos conceitos de "moderno" e "antigo". O referido autor sintetiza a dicotomia trazida juntamente com a evolução tecnológica: "É por conta dessa culturalização e sociologização das máquinas e dos avanços científicos que as apoiam que toda tecnologia está cercada de formas de exclusão e de inclusão" (2006, on-line).

Ainda, é preciso cuidar para não cair nas mesmas falácias que Soares (1995) expõe acerca da difusão do alfabetismo. É preciso ter em mente que o letramento digital, por si só, não vai levar, automaticamente, ao desenvolvimento econômico (tanto individual quanto coletivo) ou cognitivo, nem, instantaneamente, propiciará a inclusão social integral.

Não se trata aqui de rejeitar novas tecnologias sob o pretexto de que são apenas e simplesmente segregadoras. Novaes e Dagnino bem frisam que "[...] não cabe frear, limitar o desenvolvimento científico e tecnológico, voltar pra Idade Média ou retornar à simplicidade, tal como sugere Borgmann (1984, apud FEENBERG, 2002, p.15)". Os autores consideram, entretanto, que seria necessária “[...] uma radical transformação na tecnologia que potencialize suas possibilidades democráticas" (p. 205, 2004), utilizando como bússola o questionamento de como a tecnologia pode ser utilizada, reprojetada, para o desenvolvimento de uma sociedade mais democrática.

Os autores acima mencionados, em um raciocínio que pode ser comparado ao de Magda Soares (1995) já exposto sobre a própria escrita, entendem o campo da ciência e tecnologia como "um processo inerentemente social, em que elementos não técnicos (valores morais, convicções religiosas, interesses profissionais e pressões econômicas) desempenham um papel decisivo na sua gênese e consolidação (CEREZO, 2002, p. 23)" (NOVAES; DAGNINO, p. 206, 2008). Assim, as tecnologias não seriam processos autônomos, com uma lógica interna própria, mas 
seriam, majoritariamente, guiadas por critérios próprios do contexto social em que inseridas, de modo que, numa sociedade capitalista, estas incorporariam seus valores e fortaleceriam seus efeitos, como a acumulação de capital e a divisão das classes sociais. Isso permitiria a conclusão de que, atualmente, os recursos em pauta "representam muito mais um obstáculo do que um veículo para a emancipação do ser humano. " (NOVAES; DAGNINO p.207, 2008).

Tedesco (2002, p. 14), nesse sentido, esclarece que o conhecimento e a informação, na sociedade atual, estão gradualmente substituindo os antigos elementos centrais responsáveis pela distribuição de poder, como recursos naturais, força e dinheiro. 0 autor também esclarece que apesar das primeiras análises acerca das TICs como variáveis do poder terem sido otimistas sobre suas "potencialidades democratizadoras", uma sociedade com base no uso de conhecimentos "produz simultaneamente fenômenos de mais igualdade e de mais desigualdade, de maior homogeneidade e de maior diferenciação" (TEDESCO, 2002, p.15).

Apresentado o espectro dicotômico sobre a discussão que este trabalho propõe, não se trata, portanto, de exaltar ou condenar as novas tecnologias, especialmente, as concernentes à informação e comunicação. Trata-se, porém, de colocar sua incorporação sob uma análise crítica, bem como de se refletir sobre como podem ser utilizados como instrumentos a favor da democracia e da justiça social, de maneira emancipatória. Para isso, é imprescindível que se contemple o conceito de letramento digital e como sua difusão afeta práticas sociais de diferentes maneiras, de modo a se desmistificar o atual fetiche da tecnologia benéfica em todos seus aspectos.

0 aspecto que mais interessa ao escopo deste artigo, contudo, é o relacionado ao mundo do trabalho.

\section{AS DISPOSIÇÕES CONSTITUCIONAIS NORTEADORAS DA DISCUSSÃO}

A Carta Constitucional de 1988 teve como preocupação explícita a proteção da dignidade da pessoa humana, descrita em seu artigo $1^{\circ}$, inciso III, em múltiplos aspectos, por meio da garantia de diversos direitos, 
como os direitos socais, nos quais se incluem, por exemplo, o direito à educação, à saúde e ao trabalho. Igualmente, no artigo supracitado, os valores sociais do trabalho (inciso IV) encontram-se mencionados como outro fundamento da ordem jurídica brasileira.

Em seu artigo terceiro, o constituinte, ao relacionar os objetivos da República, descreveu o anseio de se "construir uma sociedade livre, justa e solidária" (inciso I), bem como "erradicar a pobreza e a marginalização e reduzir as desigualdades sociais e regionais" (inciso III).

Assim, o texto constitucional possui como um de seus objetivos incluir o cidadão na vida em sociedade com condições de uma existência digna.

Frise-se que a Constituição Federal pertence ao ano de 1988 e não reflete uma era digital como a atual, apesar de já apresentar preocupações com a seara tecnológica e a competitividade brasileira.

Assim, em 2015, a Emenda Constitucional n. 05 tratou de tentar traçar diretrizes condizentes com as novas tecnologias presentes no cotiando. Uma modificação importante foi adicionar a determinação de ser de competência material (ou administrativa) comum de todos os entes federais (União, Estados, Distrito Federal e Municípios), prover também meios de acesso à tecnologia e a pesquisa e inovação, além de à cultura, à educação, à ciência, como antes apenas constava no artigo 23, inciso V.

Ainda, a supramencionada emenda deu nova redação aos artigos do Capítulo IV, do Título VIII - "Da ordem social” da Constituição Federal, denominado agora de "Da ciência, tecnologia e inovação". Tal capítulo possui como cerne, majoritariamente, a promoção e o incentivo de "desenvolvimento científico, pesquisa, capacitação tecnológica e inovação" (BRASIL, 1988).

Também, estabelece-se que a pesquisa tecnológica deve objetivar a solução de problemas do país e o desenvolvimento do sistema produtivo em geral, conforme parágrafo segundo do artigo 218, da Constituição Federal. (BRASIL, 1988).

A Emenda, não alheia ao aspecto dicotômico das tecnologias inovadoras, estabelece oportunamente, no parágrafo 3 ํㅓ do artigo supracitado, que o Estado deverá apoiar a formação de recursos humanos nas áreas mencionadas, "inclusive por meio do apoio às atividades de extensão 
tecnológica, e concederá aos que delas se ocupem meios e condições especiais de trabalho" (BRASIL, 1988). No mesmo sentido, determina que:

$\S$ 4ํㅡ A lei apoiará e estimulará as empresas que invistam em pesquisa, criação de tecnologia adequada ao País, formação e aperfeiçoamento de seus recursos humanos e que pratiquem sistemas de remuneração que assegurem ao empregado, desvinculada do salário, participação nos ganhos econômicos resultantes da produtividade de seu trabalho. (BRASIL, 1988).

Assim, a própria Constituição vislumbra a ligação intrínseca entre novas tecnologias e a organização do trabalho, recomendando a formação e o aperfeiçoamento de recursos humanos para que o aspecto da exclusão não se sobressaia na dicotomia. Aponta, igualmente, a necessidade do estabelecimento de remuneração pela participação nos ganhos econômicos da empresa, fruto, provavelmente, da suposição lógica que a nova reorganização do trabalho em função de tecnologias não será afago ao trabalhador.

A Constituição Federal é "ponto de partida do ordenamento jurídico inteiro [...], espalha no sistema toda sua influência” (NUNES, 2011, p. 118), estabelecendo diretrizes que deveriam irradiar-se para além do mundo jurídico. Entretanto, infelizmente, ainda não é esta a realidade brasileira no tocante ao tema aqui proposto.

\section{A TECNOLOGIA E SEUS EFEITOS SOBRE 0 MUNDO DO TRABALHO}

As novas tecnologias, especialmente aquelas ligadas à comunicação e à informação, ajudam a construir um novo processo transformador da realidade, propiciando formas inovadoras de organização social.

Segundo Juan Carlos Tedesco (2002, p. 01), a transformação na organização do trabalho, nos tempos atuais, é um dos principais fatores associados ao aumento da desigualdade. Assim, é necessário refletir sobre como o letramento digital faz-se presente e determinante para inclusões e exclusões nessa nova ordem do mundo do trabalho, bem como ponderar novas nuances de preservação da dignidade da pessoa 
humana, tanto daqueles que se encontram fora do mercado de trabalho, quanto por quem está dentro deste.

Tedesco (2002, p. 03) expõe que: “as informações disponíveis permitem apreciar que a incorporação de novas tecnologias ao processo produtivo está associada à eliminação de numerosos postos de trabalho". Ainda, o autor ressalta que a maior parte dos novos postos de trabalho criados não são em setores altamente avançados tecnologicamente (2002, p.03). Pode-se inferir que um dos fatores que justificam essa afirmação é a substituição da mão de obra humana pela automação do setor.

Ao mesmo tempo, há uma tendência contínua de automação pelas indústrias e de informatização dos mais diversos setores, o que possibilita a remoção de cargos antes existentes ou mesmo a troca do contingente (antes contratado) por pessoas que dominam as práticas da era digital - geralmente, mais novas, provenientes de classes sociais mais elevadas (até porque, infelizmente, o letramento aqui mencionado é ainda restrito e dominado por certas camadas no contexto brasileiro). Convém ressaltar que troca do contingente, muitas vezes é preferida em detrimento de treinamentos dos trabalhadores que já estão ali alocados, pois, como já mencionado neste artigo, muitas vezes, o simples treinamento não propiciará a interação ou o aprendizado necessário com o meio tecnológico para que o sujeito se torne autônomo, dominante das práticas digitais, letrado digitalmente. 0 letramento vai além da mera capacitação tecnológica tal como é tratada atualmente por empresas e políticas públicas.

Desse modo, o avanço tecnológico muda a composição da estrutura empresarial, quanto aos seus cargos oferecidos e posterior desenvolvimento de carreira, alterando drasticamente o perfil necessário para integrar seus quadros.

Uma comprovação desse retrato é feita pela análise de dados de uma pesquisa realizada pelo Instituto Brasileiro de Geografia e Estatística, em 2010, denominada "Pesquisa sobre o Uso das Tecnologias de Informação e Comunicação nas Empresas", na qual se constatou que a universalidade das empresas participantes da pesquisa com 500 funcionários ou mais utilizava o computador e a Internet em suas práticas cotidianas. A taxa do uso desses equipamentos não foi universal quanto à microempresas 
e empresas no porte subsequente (de 10 a 19 funcionários), mas pode ser considerada como elevada (78\% e 94\%, respectivamente) (2010).

Com isso em mente, é fácil entender que as mudanças na organização do trabalho agravam a desigualdade social com, segundo Tedesco (2002, p. 05): “[...] a aparição de um novo fenômeno social: a exclusão da participação no ciclo produtivo.", no caso, dos majoritariamente "desconectados", ou seja, sem o domínio das práticas implicadas no letramento digital.

Isso é realmente preocupante, pois, como exposto, o trabalho é um direito inerente à dignidade da pessoa humana e sua ausência não tem pequenas consequências. Conforme expõem Grasiele Augusta Ferreira Nascimento e Regina Vera Villas Bôas:

[...] considerando que o "labor é hoje sinônimo de contribuição social e de modo de crescimento pessoal do sujeito que atua e transforma" (MARTINEZ, 2013, p. 13), não se pode deixar de perceber o sofrimento e, em algumas vezes, a desesperança vivenciada pelos milhões de brasileiros que estão excluídos do mercado de trabalho (2016, p. 32).

É inegável, portanto, que as oportunidades de trabalho, tendo em vista o atual desenvolvimento das tecnologias de comunicação e informação e a apropriação destas pelo sistema capitalista (cada vez mais dependente desses recursos), estão ligadas ao requisito básico não apenas do conhecimento de informática, mas do letramento digital. Dessa maneira, tal letramento se tornou indispensável para se integrar quadros de indústrias e até cargos no serviço público (como exemplo, pode-se destacar a inúmera quantidade de concursos de nível médio ligados ao sistema judiciário, ou a instituições como o Ministério Público, que cobram em seu conteúdo conhecimentos de informática, não apenas teoricamente: quase sempre, constituem-se de duas fases, com a segunda fisicamente frente à um computador, para digitação de textos em tempo limitado ou mesmo edição de textos em formatos indicados igualmente com limite de tempo). ${ }^{3}$

Frise-se que os grupos digitalmente excluídos são compostos, não por acaso, de pessoas de maior faixa etária e pessoas hipossuficiente, ou de classes sociais mais baixas, por conta de diversos fatores, como o custo de computadores e produtos relacionados à internet (moldem, fios, 
etc.) e a dificuldade de adquirir este tipo de letramento em certa idade. Moraes (2013, p. 7) indica que "jovens com mais renda teriam maior possibilidade de incluir-se digitalmente em comparação a pessoas mais velhas e pobres".

Adiciona-se ao exposto que a tecnologia não constitui uma barreira imutável, a qual se consegue acesso após treino constante. Isso porque uma das características dos recursos inerentes aos ramos da ciência e da tecnologia é sua auto superação, sua renovação com o passar dos anos, conforme relata Moraes:

A constante inovação observada nos produtos do ramo de informática e telecomunicação tem agravado ainda mais a situação da segregação digital. De maneira cada vez mais intensa e rápida, esses equipamentos têm se tornado obsoletos em períodos cada vez mais curtos, o que torna o processo ainda mais cruel. (2013, p. 6).

Diante da grande tendência de mecanização e implantação de TICs, bem como a mecanizar mão de obra em vários setores (e não apenas no industrial), os trabalhadores tornam-se igualmente "obsoletos" em certa velocidade. Mesmo para os profissionais que buscam atualizações constantes, a empregabilidade não está assegurada, até por risco de superqualificação - que não é competitiva, em termos salariais, em um cenário de crise.

Tedesco (2002, p. 05) sintetiza estudos recentes ressaltando que as conclusões destes sobre o assunto acabam por indicar que a nova organização do trabalho apenas consegue a incorporação de uma pequena minoria de trabalhadores de maneira estável, o que gera, para o excedente, um processo de precarização das relações de emprego, constatado por meio do aumento de contratos temporários, avulsos, de tempo parcial, aumento de cargos de subempregos e, por fim, mesmo o desemprego. Este panorama apenas agrava a exclusão social em nível macro, gatilho de um ciclo de desigualdade social que tende a se agravar.

A diferença exposta quanto aos cargos disponíveis também se associa a diferenças nos salários. Tedesco explica que:

Enquanto que os setores de alta produtividade podem ter políticas salariais generosas, os setores de serviços em que o vínculo entre salários e emprego 
é muito alto, estão obrigados a aumentar moderadamente os salários se querem que cresça o emprego. Esta dinâmica em que o emprego diminui nos setores que podem pagar bons salários e aumenta naqueles que pagam salários modestos, explica as razões pelas quais a recomposição do emprego em função da evolução tecnológica aumenta a desigualdade (2002, p. 5).

A parcela que se vê incluída nos quadros empresariais, igualmente, sofre consequências da mencionada reorganização. Apenas porque conseguiram subsistir na nova lógica imposta pelas mudanças retratadas, não significa que tenham seus direitos resguardados e condições absolutamente dignas no trabalho.

Além disso, a nova organização do trabalho, internamente, possui moldes diferenciados daqueles do passado. As novas gerações, até em decorrência de modos de pensar não lineares, reflexos dos aspectos da vida online, têm flexibilizado os sistemas hierárquicos tradicionais, apresentando estruturas com maior divisão de poder, em modelos mais horizontais que verticais, popularizando redes de cooperação e modernizando as antigas lógicas do trabalho das formas de produção de Taylor e Ford. Entretanto, Tedesco afirma que a desigualdade e a exclusão coexistem com tais mudanças, mesmo com o declínio de estruturas tradicionalmente hierárquicas, conforme explicita:

Neste esquema, todas as fases do processo produtivo são importantes e o pessoal, em qualquer nível de hierarquia que esteja, desempenha um papel crucial. [...] A maior flexibilidade está provocando a aparição de novas e mais complexas formas de relações de trabalho, em que a tensão mais importante é a que se produz entre as demandas de lucro a curto prazo por parte dos acionistas e as demandas de planejamento, compromisso e confiança que reclamam as pessoas que invertem todas suas capacidades pessoais no processo produtivo [...] (2002, p. 07).

No contexto em pauta, o trabalhador é obrigado a uma "identificação total com a empresa e com suas exigências de reconversão permanente" (TEDESCO, 2002, p.05), em troca de uma precária garantia de segurança no emprego. 0 trabalhador assim submete-se a um profundo comprometimento com a função que nem sempre vai respeitar seu direito à desconexão, ao lazer, ao convívio familiar, ou à sua dignidade humana em plenitude. 
Uma das consequências que a modernidade tecnológica trouxe ao trabalhador é a possibilidade de alcance mesmo fora do horário e ambiente de trabalho. A situação é esclarecida com absoluta nitidez:

Realmente, o trabalho nos dias atuais ganhou nova roupagem, sobretudo em virtude do avanço da tecnologia, que facilitou o desenvolvimento dos processos e promoveu a comunicação entre as pessoas, nos mais variados horários, independentemente do local onde se encontrem. Por outro lado, a facilidade de comunicação, que passou a ser imediata, ocasionou uma vinculação quase de constante do trabalhador em relação ao trabalho. Essa conexão exagerada, porém, vem acarretando sérias consequências físicas e psíquicas na saúde do trabalhador, comprometendo seu relacionamento familiar, suas atividades de lazer e, consequentemente a sua felicidade e sadia qualidade de vida (NASCIMENTO; BÔAS, 2016, p. 34).

A realidade brasileira não é diferente deste retrato. A já mencionada pesquisa sobre o Uso das Tecnologias de Informação e Comunicação nas Empresas, realizada pelo IBGE, expõe, em seus resultados, exatamente o que as autoras supramencionadas descrevem:

[...] a disseminação da telefonia móvel e a sua possibilidade de uso para voz, dados e imagens têm repercussões importantes para o setor empresarial, uma vez que possibilitam que muitas decisões sejam comunicadas e tarefas sejam executadas fora do espaço físico da empresa e do horário de trabalho. A importância do celular pode ser verificada na tabela 3, na qual verifica-se que $83,3 \%$ das empresas utilizaram celular corporativo e/ou da própria pessoa para fins de trabalho (IBGE, 2010).

O documento que expõe a consulta supracitada e seus resultados, contudo, não analisa criticamente o panorama, apontando tais porcentagens como indicadores do progresso científico das empresas brasileiras e recomendando investimento no setor de microempresas para alcançarem índices semelhantes às empresas, não apenas quanto ao uso do celular, mas quanto ao uso de TICs em geral, podendo ser citada como claro exemplo de que a ilusão de que o avanço tecnológico apenas carrega consigo benefícios é, ainda, muito forte na sociedade brasileira. 


\section{CONCLUSÃO}

Conforme exposto neste trabalho, as inovações tecnológicas possuem um impacto muito grande na vida social e nas práticas cotidianas, reorganizando diversos aspectos destas e incutindo, no senso comum, uma ideia de progresso e benesse sem limites.

Entretanto, as novas tecnologias possuem um caráter dicotômico, podendo servir tanto como mecanismos de inclusão quanto de exclusão, não propiciando necessariamente a evolução social prevista ou desejada pelos seus entusiastas. Os conceitos de letramento e letramento digital tornaram-se importantes e necessários para o desenvolvimento planejado de políticas públicas de inclusão social visando a anulação da mencionada dualidade. Não se trata, contudo, de condenar o uso desses recursos, porém, é necessário ter em mente tal dualidade para se pensar maneiras de democratizá-los e amenizar seus impactos, para que sejam propulsores da igualdade, e não perpetuadores de desigualdades e diferenças.

As relações do mundo do trabalho também sofreram transformações e tiveram seus parâmetros para inclusão ou exclusão da cadeia produtiva modificados. $O$ letramento digital hoje é, certamente, condição básica de acesso aos melhores cargos dos mercados, que diminuíram em proporção drasticamente com a automação e a reorganização das relações de trabalho. Como uma das consequências, crescem os contratos temporários de trabalho, em tempo parcial, subempregos, e outras modalidades.

0 letramento digital não apenas faz-se crucial para o acesso ao mundo do trabalho, como remodela a vivência dos que estão já nele incluídos, nem sempre de uma maneira positiva. $\mathrm{O}$ uso de novas tecnologias de informação e comunicação permitem que o trabalhador seja alcançado mesmo fora do ambiente laboral e do horário da jornada, dando outros parâmetros à subordinação. Dessa forma, é fácil perceber a potencialidade danosa dessas tecnologias ao lazer e à saúde psicológica do trabalhado, que não consegue se desconectar do trabalho.

Apesar dos ditames constitucionais acerca do assunto, ainda há muito o que ser feito para que haja condições de igualdade de participação nas práxis sociais, incluído a de exercer um trabalho, direito não apenas social, mas também direito fundamental. 


\section{NOTAS}

1 São características independentes. Segundo Buzato (2006), a diferença reside juntamente na noção de prática social. 0 analfabeto pode ser considerado letrado por dominar as práticas sociais em que a escrita tem papel significativo, ao se locomover pela cidade, ao exercer sua cidadania por práticas como o voto, o casamento, etc. Kleiman esclarece que uma pessoa analfabeta que percebe a função de cartas, etiquetas, rótulos, consegue participar, mesmo minimamente, das práticas letradas de seu grupo. (2005, p. 14).

2 Muitos autores tentam encontrar uma definição etária para a geração $Y$, definindo assim os que nascem entre meados de 1980 até o meio da década de 90. É preciso destacar, porém, que no contexto brasileiro, em qual educação formal e inclusão digital ainda se apresentam como um desafio marcado por desigualdades, dificilmente é possível estabelecer um conceito geracional. Os autores Oliveira, Piccinini, Bitencourt, esclarecem: "desta forma, temos evidências que no contexto latino americano, sobretudo o brasileiro, quando se fala em Geração Y estamos falando de um grupo pertencente a um estado superior, que não representa, portanto, a totalidade dos jovens brasileiros [...] existem os representantes da Geração Y que cultuam valores e têm um modo de vida semelhante ao vivenciado por jovens de países desenvolvidos, mas estes são minoria" (2012, p. 555-556).

3 Assim foram os últimos concursos para os cargos de escrevente judiciário e oficial do Ministério Público, ambos do estado de São Paulo, realizados nesses últimos 3 anos.

\section{REFERÊNCIAS}

BRASIL. Constituição (1988). Constituição [da] República Federativa do Brasil de 1988. Disponível em: http://www.planalto.gov.br/ccivil_03/Constituicao/ Constituiçao.htm>. Acesso em: 10 mar. 2017.

BUZATO, M. E. K. Letramentos Digitais: um lugar para pensar em Educação, Internet e oportunidades. III Congresso Ibero-Americano EducaRede. São Paulo, 29 maio 2006. Disponível em:<http://www.academia.edu/1540437/ Letramentos_Digitais_e_Forma\%C3\%A7\%C3\%A3o_de_Professores $>$. Acesso em: 16 fev. 2017.

CEREZO, J. Ciência, tecnologia e sociedade. In: SANTOS, L. (Org.). Ciência, tecnologia e sociedade: o desafio da interação. Londrina, Iapar, 2002.

IBGE. Pesquisa sobre o uso das tecnologias de informação e comunicação nas empresas. Rio de Janeiro: IBGE, 2010. Disponível em: < https://ticempresa. ibge.gov.br/index.php?option=com_content\&view=article\&id=45\&Itemid=12>. Acesso em 08 mar. 2017.

KLEIMAN, A. B. Letramento na contemporaneidade. Bakhtiniana. São Paulo, p. 72-91, ago./dez. 2014. Disponível em: <http://www.scielo.br/pdf/bak/v9n2/ a06v9n2.pdf.>. Acesso em 03 mar. 2017. 
. Preciso "ensinar" o letramento? Não basta ensinar a ler a escrever? Campinas: CEFIEL/UNICAMP, 2005.

. O impacto identitário das novas tecnologias da informação e comunicação. In: MAGALHÃES, I; CORACINI, M. J. \& GRIGOLETTO, M. (Orgs.). Práticas identitárias: língua e discurso. São Paulo: Editora Claraluz, 2006, p. 119-132.

MARCUSCHI, L. A. Da fala para a escrita: atividades de retextualização. 2.ed. São Paulo: Cortez, 2001.

MORAES, F. D. Noções sobre segregação e tecnologias de informação e comunicação. Revista Eletrônica Geoaraguaia. v. 3, n. 1, p. 1-18. jan/jul. 2013. Disponível em: < https://dialnet.unirioja.es/descarga/articulo/4340681.pdf > Acesso em: 25 fev. 2017.

NASCIMENTO, G. A. F.; BÔAS, R. V. V. Trabalho, lazer e felicidade: reflexos do trabalho contemporâneo na vida do trabalhador. In: COSTA, M. M. M.; LEAL, M. (Orgs.). Fundamentos constitucionais das políticas públicas nos direitos sociais. Águas de São Pedro: Livronovo, 2016. p. 31-50.

NOVAES, H.; DAGNINO, R. O Fetiche da Tecnologia. Revista ORG \& DEMO. v. 5, n. 2, p. 189-210 2004. Disponível em: <http://revistas.marilia.unesp.br/index. php/orgdemo/article/viewFile/411/311>. Acesso em 22 fev. 2017.

NUNES, R. Manual de introdução ao estudo do direito. 10. ed. São Paulo: Saraiva, 2011.

OLIVEIRA, S. R.; PICCININI, V. C.; BITENCOURT, B. M. Juventudes, Gerações e Trabalho: é possível falar em geração Y no Brasil?. Revista 0\&S. v. 19, n. 62, p. 551-558, jul./set. 2012. Disponível em: <http://www.scielo.br/pdf/osoc/ v19n62/10.pdf > Acesso em 03 mar. 2017.

SOARES, M. B. Língua escrita, sociedade e cultura: relações dimensões e perspectivas. Revista Brasileira de Educação. Belo Horizonte, Anped, set./dez. n. 0, 1995. Disponível em: < http://anped.tempsite.ws/novo_portal/rbe/ rbedigital/ RBDE0/RBDE0_03_MAGDA_BECKER_SOARES.pdf> Acesso em: 20 fev. 2017.

TEDESCO, J.C. Os fenômenos de segregação e exclusão social na sociedade do conhecimento. Cadernos de Pesquisa. n. 117, p. 13-28, nov. 2002. Disponível em: < http://www.scielo.br/pdf/cp/n117/15550.pdf>. Acesso em: 10 mar.2017. 
UNESCO (1978). Recommendation concerning the Internacional Standardization of Educational Statiscs. Paris: UNESCO. Disponível em: < http:// unesdoc.unesco.org/images $/ 0011 / 001140 / 114032$ e.pdf\#page=183> Acesso em 20 fev. 2017.

Recebido em: 18-5-2017

Aprovado em: 24-1-2018

\section{Luisa Nascimento Bustillo}

Mestranda em Direito pelo Centro Universitário Salesiano de São Paulo (UNISAL); graduada em Direito pela Pontifícia Universidade Católica de Campinas e em Letras pela Universidade Estadual de Campinas (2015); bolsista PIBIC/CNPq (2012-2013) para desenvolvimento de Iniciação Científica na Puc-Campinas; integrante do grupo de pesquisa "Minorias, discriminação e efetividade de direitos" (UNISAL/CNPq). E-mail: luisanascimentob@gmail.com

Centro Universitário Salesiano de São Paulo, São Paulo, Lorena. Rua Dom Bosco, 284. Centro. CEP 12600-100 - Lorena, SP - Brasil

\section{Grasiele Augusta Ferreira Nascimento}

Pós-doutora em Democracia e Direitos Humanos pela Universidade de Coimbra/Ius Gentium Conimbrigae (2014); doutora em Direito pela Pontifícia Universidade Católica de São Paulo (2002); mestre em Direito pela Pontifícia Universidade Católica de São Paulo (1997), ; diretora Operacional do Centro Universitário Salesiano de São Paulo, unidade de ensino de Lorena/SP.; professora e Pesquisadora do Programa de Mestrado em Direito e Professora do Curso de Direito do Centro Universitário Salesiano de São Paulo. E-mail: diretora.operacional@lo.unisal.br

Centro Universitário Salesiano de São Paulo, São Paulo, Lorena. Rua Dom Bosco, 284. Centro. CEP 12600-100 - Lorena, SP - Brasil 